\title{
Estudo de meio de cultura para Bacillus Subtilis CCT516 utilizando técnica de planejamento experimental
}

\author{
JÖNK, M. W. ${ }^{1}$, TODESCATO, D. ${ }^{1}$, MAASS, D. ${ }^{1}$, OLIVEIRA, D. ${ }^{1}$, ULSON DE \\ SOUZA, A. A. ${ }^{1}$, GUELLI U. SOUZA, S. M. A. ${ }^{1}$ \\ ${ }^{1}$ Universidade Federal de Santa Catarina, Departamento de Engenharia Química e \\ Engenharia de Alimentos \\ E-mails para contato: marthinawj@gmail.com, selene@enq.ufsc.br
}

\begin{abstract}
RESUMO - O Bacillus subtilis é uma das 40 espécies de Bacillus mais estudadas na área de biotecnologia. Sua alta capacidade produtora de biossurfactantes torna-o uma bactéria de grande aplicabilidade na biotecnologia industrial e ambiental. $\mathrm{O}$ presente trabalho visou à formulação de um meio para o máximo crescimento celular. Com o intuito de avaliar a influência dos fatores físicos e quantidade de nutrientes empregada aos reatores, foi utilizada a técnica de planejamento experimental fracionário. A partir dos resultados verificou-se que a concentração de peptona, extrato de carne, extrato de levedura, concentração de $\mathrm{NaCl}$ e a influência da agitação são estatisticamente significativos, fatores estes, que intensificaram o crescimento do B. subtilis. Também foi observado que as interações entre agitação e quantidade de proteínas, bem como agitação e temperatura geram efeito positivo. Já as interações entre temperatura e os parâmetros concentração de $\mathrm{NaCl}$ e extrato de levedura possuem efeito negativo.
\end{abstract}

\section{INTRODUÇÃO}

Bacillus subtilis, uma das 40 espécies do gênero Bacillus, são bactérias autóctones do solo, do tipo gram-positivas, aeróbias facultativas, não fotossintetizantes e com maior atividade em temperaturas médias de 25 a $35^{\circ} \mathrm{C}$, mas com alta capacidade de produzir esporos quando em condições adversas (PORTER, 1976).

Esse gênero específico de bactérias, B. subtilis, destaca-se por possuir capacidade natural para secretar antibiótico (bacitracina) e biosurfactante (surfactina) que são compostos de alto valor biotecnológico.

Bacitracina é o antibiótico mais utilizado no tratamento de infecções digestivas por atuar sobre a parede celular de bactérias do tipo gram positivas. Quando no sistema disgestivo de porcos, coelhos, frangos, entre outros, influencia na absorção de nutrientes o que promove crescimento e controle sobre doenças entéricas (CASTELLANOS et al., 2011). 
Surfactantes são os compostos que agem nas interfaces químicas, sendo utilizados principalmente nas indústrias texteis, para detergência, e alimentícias, como emulsificantes. Os biosurfactantes, como a surfactina, produzida por B. Subtilis, são vantajosos em relação aos surfactantes sintéticos, atualmente utilizados em alimentos e cosméticos, por sua maior biodegradabilidade e baixa toxicidade (BARROS et al., 2007).

Além da secreção de metabólitos extracelulares de grande relevância, B. subtilis desempenha funções de alta aplicabilidade na área agrícola. Estudos comprovaram sua interação mutualística benéfica com o rizoma de vegetais, o que o clascifica como um bioregulador e promotor do crescimento de plantas. Surge, então, o interesse em encontrar um meio nutritivo que forneça condições para sua atividade plena (JAMIL, 2007; ARAÚJO et al., 2005).

Um meio para a cultura de células deve suprir todas as exigências para o crecimento microbiano: as condições físicas, como temperatura e agitação e os compostos essenciais que micro-organismos são incapazes de produzir. Neste trabalho a concentração de nitrogênio (extrato de levedura), concentração de proteínas (peptona e extrato de carne) e concentração de sal $(\mathrm{NaCl})$, bem como as condições físicas impostas aos reatores (agitação e temperatura), foram avaliadas como parâmetros de um planejamento experimental fatorial $2^{(6-1)}$ com o intuito de identificar sua influência no crescimento do Bacillus subtilis.

\section{MATERIAIS E MÉTODOS}

\subsection{Obtenção das curvas de crescimento do B. subilis}

Inoculou-se duas alçadas de células do em frascos Erlenmeyer de $50 \mathrm{ml}$ contendo meio de crescimento previamente autoclavado a $121{ }^{\circ} \mathrm{C}$ por $20 \mathrm{~min}$. O mesmo foi deixado em incubadora por 24 horas a $24^{\circ} \mathrm{C}$ e $150 \mathrm{rpm}$. Posteriormente transferiu-se 2,5 $\mathrm{mL}$ de inóculo para outro frasco Erlenmeyer de $100 \mathrm{ml}$ contendo meio de crescimento esterilizado, que permaneceu em incubadora por mais 18 horas nas condições definidas pelo procedimento experimental.

Amostras de $1 \mathrm{ml}$ foram pipetadas, diluídas e avalidas por turbidimetria em determinados intervalos de tempo para que a curva de crescimento celular em cada reator fosse construída.

\subsection{Planejamento experimental}

Optou-se por um planejamento fracionário $2^{(6-1)}$ com hexaplicata do ponto central, gerando um total de 38 experimentos. Após a escolha do tipo de planejamento, definiram-se os níveis de variação codificados $-1,0$ e +1 , para cada um dos três fatores 
em estudo. As variáveis e seus respectivos níveis de variação são mostrados na Tabela 1.

Tabela 1 Definição de parâmetros para o planejamento experimental

\begin{tabular}{cccc}
\hline Parâmetro & -1 & 0 & +1 \\
\hline (1) Concentração de extrato de carne $(\mathrm{g} / \mathrm{L})$ & 0,5 & 1,0 & 1,5 \\
(2) Concentração de peptona $(\mathrm{g} / \mathrm{L})$ & 2,5 & 5,0 & 7,5 \\
(3) Concentração de extrato de levedura $(\mathrm{g} / \mathrm{L})$ & 1,0 & 2,0 & 3,0 \\
(4) Sal NaCl $(\mathrm{g} / \mathrm{L})$ & 2,5 & 5,0 & 7,5 \\
(5) Agitação $(\mathrm{rpm})$ & 100 & 150 & 200 \\
(6) Temperatura $\left({ }^{\circ} \mathrm{C}\right)$ & 28 & 32 & 36 \\
\hline
\end{tabular}

\section{RESULTADOS E DISCUSSÃO}

\subsection{Cinéticas de crescimento}

O Figura 1 apresenta a tendência das curvas de crescimento microbiano obtidas pelo planejamento experimental.

Figura 1 Curvas de crescimento.

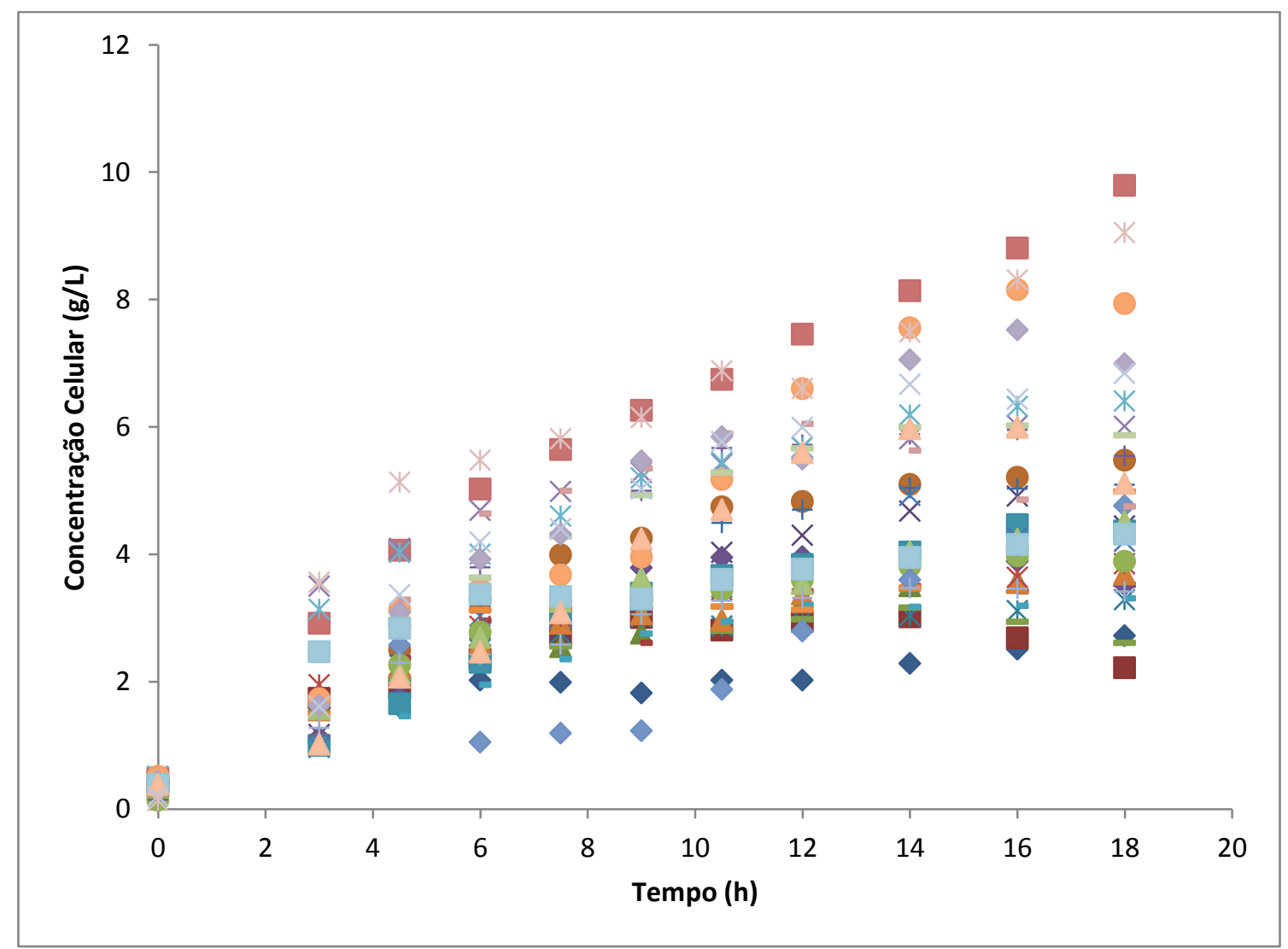


Existem quatro fases de crescimento bacteriano: a fase lag, a fase log, a fase estacionária e a fase de morte. $\mathrm{Na}$ fase $\log$, o crescimento é mais ativo atingindo um tempo de geração constante. A fase log é o momento de maior atividade metabólica sendo o preferido para fins industriais, já que o produto precisa ser produzido de maneira eficiente. Considerou-se que a fase log, ou exponencial, ocorreu no intervalo inicial de tempo de 14 horas. Passado este período a concentração celular permaneceu constante devido à aglomeração das celulas, o que impossibilia a medida por turbidimetria (TORTORA et al., 2012).

\subsection{Estudo estatístico dos fatores de crescimento}

Por meio dos resultados obtidos nos experimentos, realizou-se uma análise dos efeitos dos seis fatores estudados, em relação à resposta do experimento (crescimento celular).

Tabela 2 Resultados estatísticos do planejamento experimental

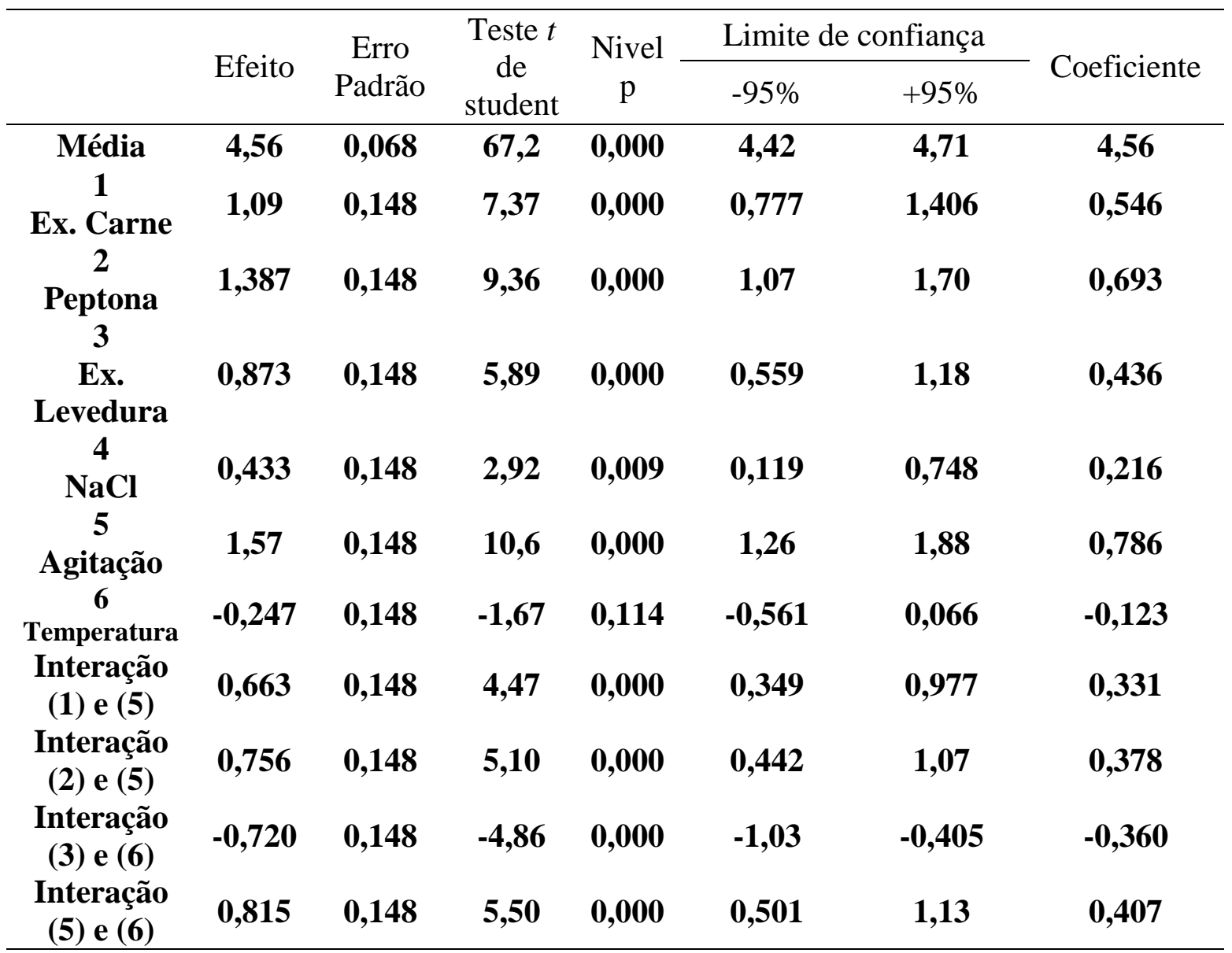

$\mathrm{R}^{2}=0,95466$; Erro Residual=0,2157371; Ajuste: 0,89515

A coluna nível p de significância indica o quão representativos são os resultados obtidos. Estatisticamente pretende-se um valor p mínimo igual a 0,05. Ou seja, ao menos uma a cada vinte replicatas será análoga ao estudo. $\mathrm{O}$ efeito, na primeira coluna 
da tabela, mensura a proporcionalidade linear da variável dependente aos fatores e suas interações.

A partir dos dados da Tabela 2, conclui-se que é positiva para o crescimento do B. subtilis a influência da agitação, da concentração de extrato de carne, da concentração de peptona, de extrato de levedura e de $\mathrm{NaCl}$, nesta ordem descrescente de relevância. Já a temperatura, por si só, não mostrou-se estatisticamente significativa ( $\mathrm{p}=$ $0,114)$.

Quando levadas em conta as interações entre os parâmetros, é significante o efeito favorável provocado pela agitação associada ao extrato de carne, peptona ou à temperatura. Entretanto, quando associada ao extrato de levedura, a temperatura prejudica o crescimento do B. subtilis.

Figura 2 Gráfico do pareto para o planejamento experimental.

Gráfico de Pareto para os Efeitos sobre o Crescimento Celular

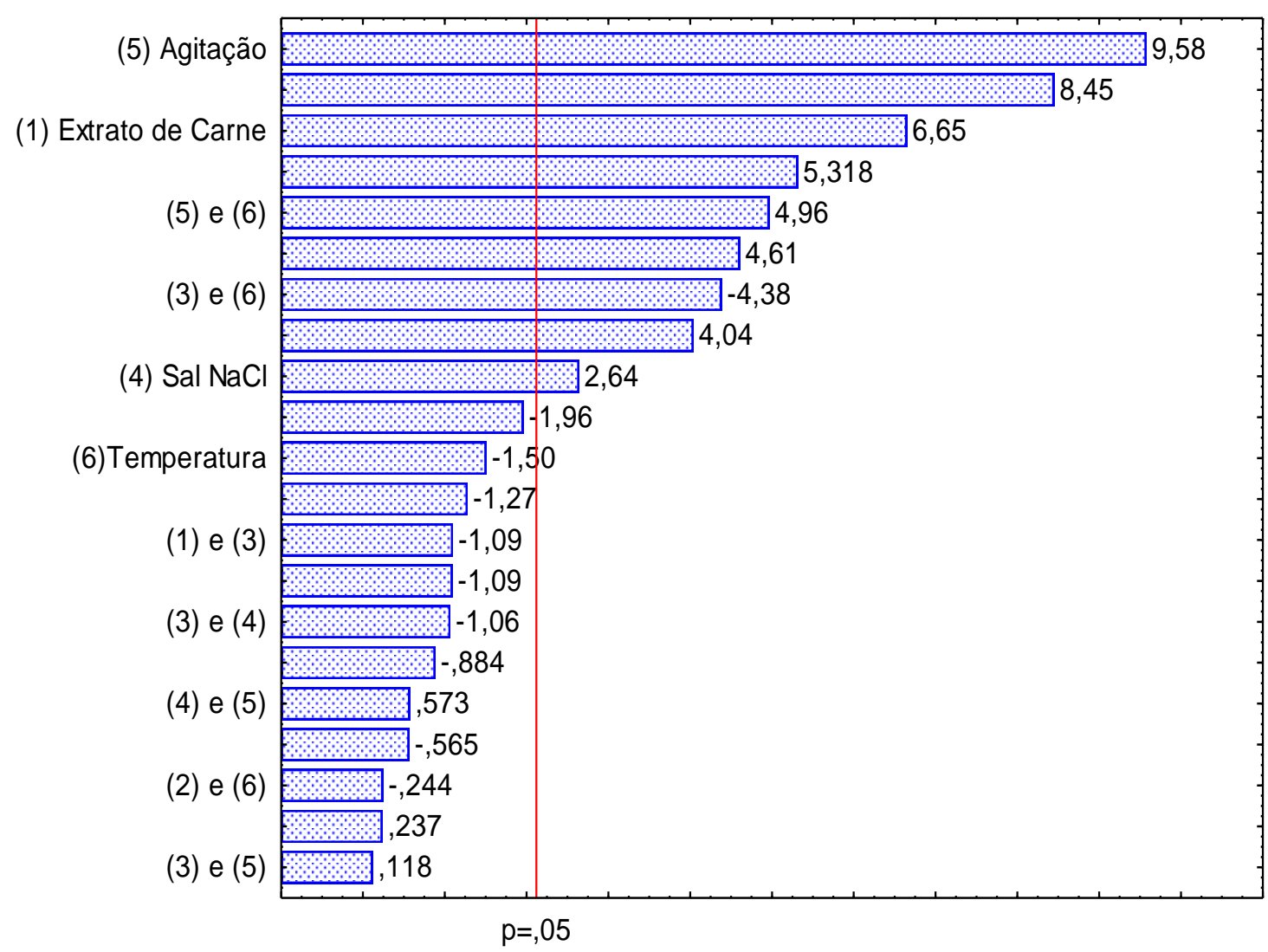

Caráter uniforme dos efeitos estimados (valores absolutos)

A Figura 2 aponta os fatores estatisticamente significativos. Todos os parâmetros e interações, cujas colunas ultrapassam a linha vemelha (representando nível de significância igual a 0,05 ) são importantes nas faixas estudadas. 
A Figura 3 representa secções horizontais projetadas sobre uma superfície bidimensional e retrata como as interações entre os fatores estudados pelo planejamento experimental interferem no crescimento microbiológico do Bacillus subtilis.

Figura 3 Superfície de resposta do crescimento pela interação entre agitação e concentração de peptona.

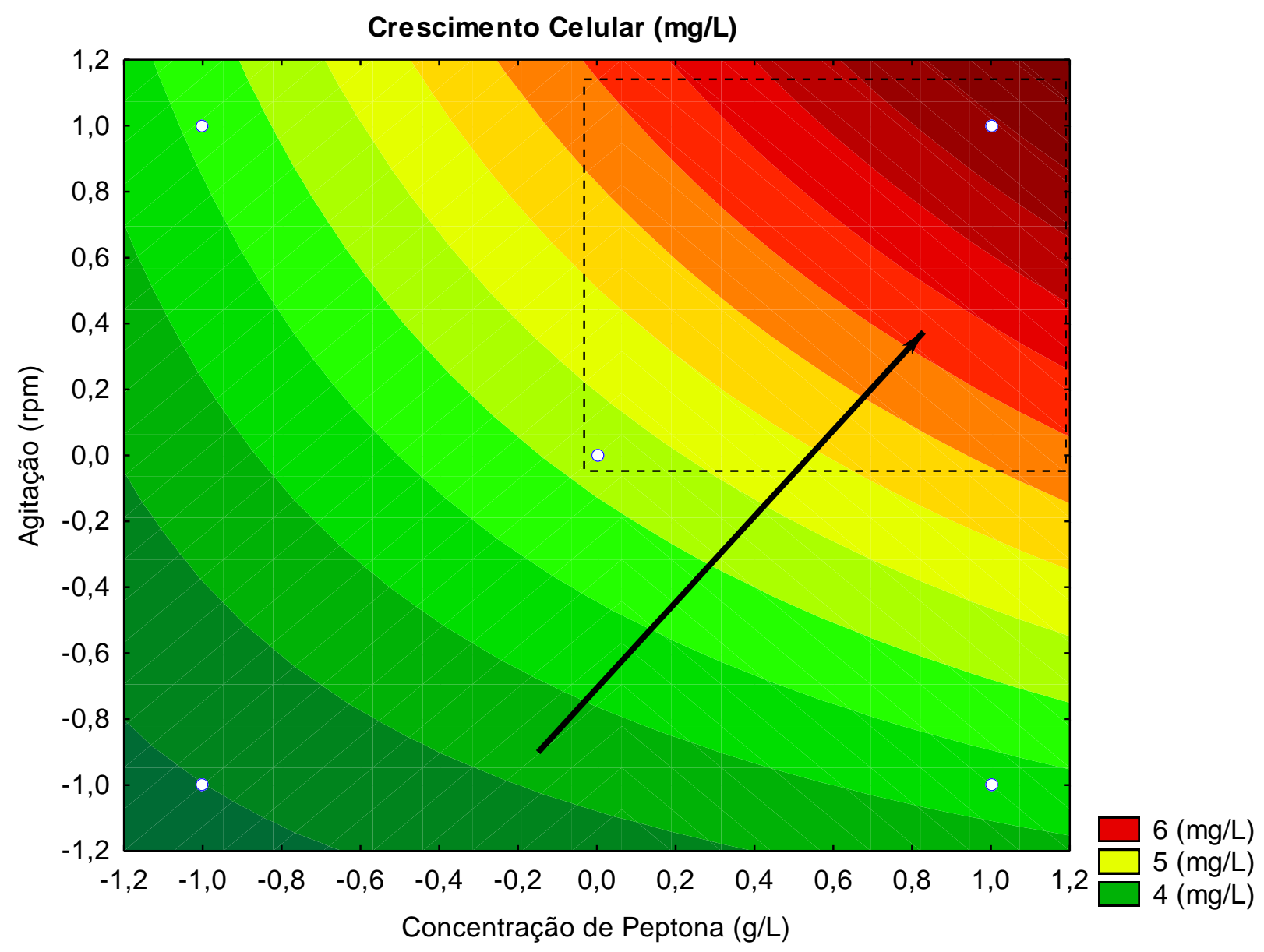

Cada ponto do gráfico representa uma combinação dos fatores, que variam entre os níveis máximo (1), central (0) e mínimo (-1) do planejamento, enquanto as cores definem o crescimento da variável dependente, no caso, o crescimento celular. Entre o par agitação e concentração de peptona nota-se que o crescimento celular só atinge concentrações maiores que $5,0 \mathrm{~g} / \mathrm{L}$ no quarto superior direito, onde os níveis são máximos tanto para agitação $(200 \mathrm{rpm})$ quanto para a concentração de peptona (7,5 g/L). Além disso as curvas de nível nessa mesma região estão menos espaçadas, indicando que a taxa de variação da concentração celular é muito maior quando comparada aos outros pontos, ou, em outras palavras, pequenas variações nos parâmetros geram consideráveis alterações nos resultados.

\subsection{Carbono}


Segundo TORTORA et al. (2012), todos os micro-organismos requerem uma fonte de carbono; os quimio-heterotróficos, como o B. subtilis, utilizam uma molécula orgânica, e os autotófricos em geral utilizam o dióxido de carbono. Isso explica a proporcionalidade entre a concentração de extrato de carne e a concentração celular. Quanto maior a disponibilidade de carbono, maior a tendência de crescimento celular.

\subsection{Oxigênio}

Como se sabe, do ponto de vista bioquímico, o oxigênio é o elemento que vincula o fim da cadeia respiratória à glicólise e ao ciclo de Krebs, e ainda permite o armazenamento de energia através da transformação de moléculas de ADP para ATP. Sabe-se também que o Bacillus em questão é aeróbico facultativo, porém para cultivá-lo em condições anaeróbias é necessário nitrato ou nitrito como aceptor de elétrons ou por fermentação. Por outro lado, a agitação permite ampliar a área de contato entre a solução e o headspace do reator, além de forçar a transferência de massa por convecção, fatores determinantes à solubilização do oxigênio. Consequentemente, quanto mais intensa a agitação dos bioreatores, maior a concentração final de células do Bacillus (NAKANO e ZUBER, 1998).

\subsection{Nitrogênio}

O nitrogênio constitui cerca de $14 \%$ em massa seca da célula bacteriana, e é também importante para a síntese de proteínas e ácidos nucleicos, assim como para síntese de ATP, molécula responsável pelo armazenamento e pela transferência de energia dentro da célula. Interpreta-se a relação de equivalência entre o extrato de levedura e peptona (fonte de nitrogênio) e a concentração de células, como a necessidade de ATP para a divisão binária das células, entre as outras funções do nitrogênio para a bactéria (TORTORA et al., 2012).

\section{CONCLUSÃO}

Através do planejamento experimental demonstrou-se que o fator de maior influência sobre o crescimento celular do Bacillus subtilis é a agitação; além disso concluiu-se que a temperatura não é estatisticamente significativa na faixa entre 28 e 34 graus. Em determinadas condições, este gênero de bactérias cumpre as exigências do processo biotecnológico, adaptando-se facilmente em meios de cultura sem altos custos energéticos e/ou financeiros.

\section{REFERÊNCIAS BIBLIOGRÁFICAS}


ARAUJO, F. F., HENNING, A., HUNGRIA, M. Phytohormones and antibiotics produced by Bacillus subtilis and their effects on seed pathogenic fungi and on soybean root development. World J. Microbiol. Biotechnol., v. 21, p. 1639-1645, 2005.

BARROS, F. F. C., QUADROS, C. P., MAROSTICA JUNIOR, M. R., PASTORE, G. M. Surfactina: propriedades químicas, tecnológicas e funcionais para aplicações em alimentos. Quím. Nova, v. 30, n. 2, p. 409-414, 2007.

CASTEllanOS, C. V., PEÑA, V. P., ARIAS, J. P. Validación del método analítico para la cuantificación de bacitracina. Revista Cubana de Farmácia, v. 45, n. 2, p. 216$225,2011$.

JAMIL, B., HASAN, F., HAMEED, A. Isolation of bacillus subtilis MH-4 from soil and its potential of polypeptidic antibiotic production. Pak. J. Pharm. Sci., v. 20, n. 1, p. 26-31, 2007.

NAKANO, M. M., ZUBER, P. Anaerobic growth of a "strict aerobe" (Bacillus subtilis). Annu. Rev. Microbiol., v. 52, p. 165-190, 1998.

PORTER, J R. Antony van Leeuwenhoek: Tercentenary of his discovery of bacteria. Bacteriolog. Rev., v. 40, n. 2, p. 260-269, 1976.

TORTORA, G. J., FUNKE, B. R., CASE, L. C. Microbiologia - 10. edição - Porto Alegre: Artmed, 2012. 